\title{
"Everyone Has Their Own Places": Mapping as a Storied Approach to the Study of Youth Identity
}

\author{
ERIN SPRING \\ University of Calgary
}

\begin{abstract}
This article highlights part of my work with ten 16 and 17-year-olds at two Canadian secondary schools. My multiple case study sought to make visible my participants' stories of place: how did they construe the role of place within their own lives? How did they record their journeys within, through, and between places? I share how my participants articulated their place-identities as dynamic encounters rather than fixed surfaces (Massey, 2005; Ingold, 2016). Employing story-mapping as a research method encouraged my participants to articulate their lives in their own terms, affording me the opportunity to understand how they negotiated their identities.
\end{abstract}

\section{Introduction}

In The Wild Places (2007), literary critic Robert Macfarlane distinguishes between grid maps (or road maps) and story maps, suggesting that grid maps reduce the world to data and thus "record space independent of being" (p. 141). In privileging precision, grid maps eliminate all subjectivity from the represented space. Conversely, Macfarlane explains story-maps as perceptual and embodied, as being "records of specific journeys" (p. 141) that are "alert to a landscape's volatility as well as its fixtures" (p. 145). Macfarlane's distinction leads me to wonder how youth make sense of place, and how their stories of place might be generated. In a society that privileges data, and largely perceives youth development as a linear process (Farrugia \& Wood, 2017), what can be learned from attuning to the story-maps of young people? What might their representations reveal about the ways in which they understand themselves and the complex worlds they live in?

This article highlights part of my work with ten 16 and 17-year-olds at two Canadian secondary schools. The purpose of my multiple case study was to make visible my participants' stories of place: how did they construe place within their own lives? How did they record their journeys within, through, and between places? (Spring, 2015; Spring, 2016; Spring, 2018). This article shares how my participants articulated their "literacies of place" (Mills \& Comber, 2013, p.420) as dynamic encounters rather than fixed surfaces (Massey, 2005; Ingold, 2016). Employing story-mapping as a research method encouraged my participants to "construct accounts of their lives in their own terms" (Holloway \& Valentine, 2000a, p. 8), therein affording me the opportunity to understand how they imagined and negotiated their identities through their engagement with and creation of a range of maps. Mapping became a kind of literacy that provided these youth the agency to represent their multiple place-relationships.

This study adds to the growing body of qualitative research invested in the spatial identities of young people (Haukanes, 2013; Farrugia et al., 2015; Farrugia, 2016; Cuervo \& Wyn, 2017; Rönnlund, 2020). While this article has an interdisciplinary theoretical framework, I draw on spatial approaches to literacy research, a turn which has illuminated 
the importance of place on young people's literacies and identities (Leander \& Sheehy, 2004; Sheehy, 2009; Charlton et al., 2011; Charlton et al., 2014). It is vital for researchers who are interested in the experiences of youth to know more about their place-relations $a s$ storied by them. I share Caitlin Cahill's (2000) assertion that "how teenagers define their environmental transactions is intimately bound with the way in which they construct their identities" (p. 251). If we seek to understand the experiences or "street literacies" (p. 252) of young people, and if we conceptualize them as capable of producing their own meaning as active participants in our society (Holloway \& Valentine, 2000b; Skelton \& Valentine, 1998), as I do, then it is vital that we directly invite them to voice their realities. My work contributes through its focus on adolescence and demonstrates the tremendous potential for place to incite identity-work with young people in the literacy classroom. My classroom-based research insists that focusing on the nuances of adolescent's spatial encounters, within and beyond school walls, averts our gaze away from the classroom, allowing us to capitalize on the diverse perspectives that shape their unfolding identities.

Before outlining the particular details of this study, some foundational concepts are considered.

\section{Key Concepts}

Here, I take up the work of cultural geographer Doreen Massey and social anthropologist Tim Ingold, both of whom resist fixed conceptualizations of place and the social world. Rather than representing place as static, as a surface to be conquered, or an area to be enclosed with borders, Massey (2005) theorizes place as a "simultaneity of stories-so-far" (p .9) or as a "bundle of trajectories" (p. 47) where histories and stories converge. Emphasizing relationality, she argues that places are always in motion and therefore always unfinished or incomplete. From the perspective of mapping, then, Massey (2005) insists that representing place as a horizontal surface is impossible because space is constantly on the move. While she acknowledges that this vision of place presents a challenge to mapping, she makes the plea for cartographers "to disorient, to defamiliarise, to provoke a view from an unaccustomed angle" (p. 109). Massey's perspective aligns with Macfarlane's (2007) reminder that places cannot be contained by coordinates or a grid because of their reliance on stories, which are always in flux.

For Ingold (2008), place is not an environment (or what Massey might refer to as a 'surface') but a "zone of entanglement" (p. 1807). He employs the term meshwork to explain that every person is comprised of a "bundle of lines" $(2015, \mathrm{p}$. 3). These lines do not connect, but rather interweave to form a meshwork. He asserts that if we are interested in people's social experiences, we should "study the lines they are made of" $(2016$, p. 5). Ingold's concept of the path is additionally useful to my analysis. He writes: "to be [...] is not to be in place but to be along paths. The path, and not the place, is the primary condition of being, or rather of becoming" (p. 12, emphasis in original). Much like Massey's (1994) insistence that places are comprised of an intersection of social relations, Ingold's path requires us to think about place as action: we follow paths through the world, and in doing so we (and place) are always becoming, rather than being. We move along and between places rather than simply residing in them or moving across them. For both Massey and Ingold, place is where histories, stories, and identities connect and, more importantly, overlap. For Ingold (2016), place is a "knot in the meshwork" (p. 104) of lines. 
Ingold (2016) helpfully turns to mapping to illustrate two different modes of travel: wayfaring and transport. Cartographic maps, in charting transport, include borders. Any line found on a cartographic map is drawn "across the surface," (p. 87) signifying occupation -- such as railway lines or roads. Conversely, sketch maps rarely include frames or borders, and their lines signify habitation or movement because they seek to re-enact "journeys actually made" (p. 87, emphasis in original). For Ingold, lines on sketch maps are draw along rather than across. Similarly, Massey (2013) writes about train journeys: "you're not travelling across a dead flat surface that is space: you're cutting across a myriad of stories" (n.p). Because wayfaring is not about getting from one place to another, sketch maps render subjective encounters and thus cannot claim accuracy.

Massey and Ingold employ the term bundle to illustrate the relational nature of place. For Ingold (2015), place is a "bundle of lines" (p. 3), and for Massey (2005) it's a "bundle of trajectories" (p. 47). The concept of place as a bundle is central to my ensuing analysis. Massey, Ingold, and Macfarlane's writings about mapping, particularly their focus on the influence of stories, encourages me to consider how my participants' placeencounters are not fixed but are shaped by their multiple journeys along paths and through places rather than simply across them. Their stories of place are not singular but are rather bundles of encounters.

My study was not only designed to conceptualize my participants' place-relations, but to understand the ways in which place informs their unfolding adolescent identities. Identity development is understood here to be "fluid, contextually and socially negotiated, multidimensional, and intersectional" (Compton-Lilly et al., 2017, p. 122) as opposed to a linear trajectory shaped by time or a series of milestones (Farrugia \& Wood, 2017). If place is conceived as a bundle, we can likewise think about identity as not static or linear but rather something that changes over time and across space (Spring, 2015; Spring, 2017).

In the following subsections, I outline spatial approaches to literacy research and consider the implications of employing mapping as a methodological approach with youth.

\section{Place, Identity, and Adolescent Literacy}

Spatial approaches to literacy research argue that literacy practices provide methods through which we can create culture and enact our identities (Moje, 2000). Work in this area points out that if it is accepted that literacy practices are socially and culturally constructed, then place becomes a crucial unit of analysis that enables us to "explain literacy practices as flows of ideas and artifacts in webs of discourses" (Sheehy, $2013 \mathrm{p}$. 405). Consequently, understanding young people's literacies requires a consideration of the diverse places and times where these practices unfold (Mills \& Comber, 2013).

To help scholars and educators visualize "the complexity of local, everyday community literacy practices" (Street, 2017, p. 38), there has been a push for small-scale, qualitative work that illuminates the multiplicity of readers, texts, and contexts (Cliff Hodges, 2016). Margaret Mackey (2003) has called for a "thick description of interpretive acts, thick analysis, and thick theorizing" (p. 405). This disciplinary shift has resulted in a renewed focus on the lived and situated experiences of readers and has brought local communities into the spotlight (Mills \& Comber, 2016; Comber, 2016). Rather than telling a singular narrative, or seeking generalizations across contexts, spatial approaches to literacy celebrate the multiplicity of narratives, places, and identities that are created within and beyond classrooms of all kinds. 
Work in the area of spatial literacies has been taken up using a range of methodological approaches. In her empirical work in the United Kingdom, for example, Gabrielle Cliff Hodges (2010) has asked young people to consider their reading histories, and to plot these events onto the sketch of a river. The collages offer a visual understanding of the ways in which these readers' trajectories are mediated historically, temporally, and spatially. Mackey's (2016) work on the physicality of reading similarly highlights how her reading history has been shaped by her explorations of place as a child. Barbara Comber's (2016) work chronicles decades of critical literacy research in southern Australia. Her classroom-based case studies demonstrate how "learner identity and place are irrevocably connected" (p. 15), making the case for place as a springboard for literacy instruction. Comber similarly draws on Massey's work to think about place within the context of schooling. Borrowing some of Massey's language, she explains classrooms as sites of convergence, "meeting places" (2013, p. 363) where youth from various communities and contexts are "thrown together" (2016, p. 151) in a shared space. Working with Latino/a youth in a range of out-of-school settings Elizabeth Birr Moje's (2004) found that access to space "shaped the texts [the youth] consumed and produced, which in turn shaped the ways they chose to identify and were identified" (p. 30). Such examples foreground the varied intersections between places, literacies, and young people's identities and set the stage for my own investigation.

\section{Mapping as a Research Method with Adolescents}

Mapping is customarily used as a method through which young people are offered the opportunity to articulate how they navigate and experience place (Skelton \& Valentine, 1998; Farrugia, 2014). Adolescents, however, are infrequently afforded the opportunity to represent their spatial-temporal experiences visually and are therefore largely absent from methodological conversations (Spring, 2015). Tracy Skelton and Katherine Gough argue (2013) that youth hold "an urban studies presence but an urban studies absence" (p. 456). Even more frequently, rural youth constitute a gap in the literature on young people's spatial identities (Farrugia, 2014; Rönnlund, 2020). Place-based research that does involve teenagers tends to focus on the recognition that they are often excluded from public spaces (Travlou et al., 2008). While likely true, we do not know enough about how young people position themselves in relation to both public and private spaces. For my participants, in their final year of high school, place was already at the forefront of their thinking. I was led to wonder: what about the places where they do feel included, the places where they do have positive affiliations, and why might discerning these places via literacy practices be imperative to an understanding of young people's identities? I felt that mapping would provide an avenue for considering these questions.

Mapping, sometimes referred to as mental mapping, or "cognitive mapping" (Lynch, 1960; Catling, 1988; Kitchin, 1994; Gieseking, 2013) provides participants with a degree of agency as to how and what to represent. Methodologically, I am inspired by the work of Jonathan Monk (2019) who asked his London-based secondary school students to map their experiences of London while reading fictional accounts of the city in the hope that they would come to understand the intersection between their personal and literary topographies. Additionally, the work of the Writing, Reading, and Place Project (Charlton et al., 2011) has shaped my thinking about the role of literature to incite conversations about place and mapping. Much like these researchers, I similarly offered my participants 
the opportunity to sketch maps in their journals, or to map places through narrative, but I did not specify of what. Their maps therefore illuminate what they perceive to be salient places in their lives. My participants' maps were not limited to physical locations, nor were meaningful places represented temporally or linearly in relation to the life course. Instead, like the students Kimberly Powell (2010) worked with in Panama City, my participants' maps illustrate a "cartography of concepts" (p. 540) that transcend the traditional features of a grid map, moving into the realm of story (Macfarlane, 2007).

Drawing on spatial approaches to discourse analysis, which argue that "local landscapes are not blank canvases or spatial contexts but integrative and invented environments" (Pennycook, 2010, p.14), this article offers a glimpse into the lives of a selection of adolescents, living in a particular time and place. In my analysis, I understand their maps are never complete representations because of the transient nature of identity and place (Kitchin and Dodge, 2007; Gieseking, 2013). Below, drawing on my participants' varied responses illustrates the ways in which mapping became a literacy practice that allowed them to have agency in articulating, representing, and re-storying their identities. I also attend to the ways in which their responses correspond with the theories of place and mapping highlighted above, so as to highlight how my participants themselves understood and represented place and identity as fluid and storied, as opposed to static.

\section{Research Design}

For this project, I spent time with adolescents living in two Ontario communities: a multicultural neighbourhood in Toronto ("Kirkville") and a predominantly white rural community 250 kilometers from the nearest city ("Lakeside"). Chloe, Irina, Alice, Victoria, and Calla lived in Kirkville. Two were recent immigrants and three were born in Toronto. Liam, Sophie, Paige, Norah, and Thea lived in Lakeside and were all white and Canadian born. None of them had travelled far beyond their rural community and their school was not visibly diverse. In both cases, I visited the school, presented my project, and asked for volunteers. We met outside of classroom time in the library. Due to the geographical distance between my two case sites, the urban and rural participants never met.

In each location, the students read two young adult novels prior to meeting as a group: Clare Vanderpool's Moon Over Manifest (2010) and Tim Wynne-Jones' Blink and Caution (2011). Both books explore explicitly place-based themes. After individual readings, we came together in the school library for a series of reading discussion groups. While I was present for these sessions, the unstructured conversations were facilitated by the participants themselves. Firstly, the focus of the discussion groups was to understand their readings of fictional places. Blink and Caution, for example, is set in Toronto. I wondered what it was like for my urban participants to read about their home city. Secondly, I wanted to understand how the act of reading compelled my participants to deliberate on the role of place within their own lives.

Outside of our group discussions, each participant independently mapped, sketched, and wrote narratives in a project journal. I provided participants with a list of responses they could consider but ultimately let them decide how to represent their experiences. Lastly, I conducted semi-structured interviews with each participant. As "drawing and map making [do] not show in full spectrum the maker's spatial relationship 
with his/her surroundings world," (Travlou et al., 2008, p. 311) it was important that my participants' interpretations led my analysis. Participants were asked about their maps in the interview.

This article turns the spotlight on a selection of maps that were created by my participants in their journals. Some are visual maps; others take the form of an oral "cartographic narrative" (Travlou et al., 2008, p. 311) or a "spoken cartography" (Macfarlane, 2007, p. 141). Sharing a selection of story-maps created by my participants now allows me to illustrate how mapping became a kind of literacy that provided these young people with an opportunity to explore their place-identities.

\section{Emergent Understandings of Place and Identity}

Before turning to my participants' maps, I share several discussion-group excerpts that illustrate how they conceptualized mapping and place in response to the novels we shared. While their text-based reflections are not the focus of this article (see Spring, 2015; Spring, 2016; Spring, 2018), these extracts highlight the ways in which my participants, without my prompting, or any previous knowledge of underlying spatial theories, understood the complexities of place.

In Vanderpool's (2010) Moon Over Manifest, on the protagonist's (Abilene) first day of school, the following discussion occurs between her and her classmate:

"Well, where are you from? Where's your home?"

That question always came up real quick. It was a universal. And I was ready for it.

"All over. My daddy says it's not down on any map. True places never are." (Vanderpool, 2010, p. 29)

At both case sites the participants reflected on the concept of true places:

Paige: I think you can have a place [pause] you can have a place on a map but it means a lot more to you than just a place on a map. Like, the way it is on a map does not represent what it means to you [...] Like everyone has their own places [...] like there will be places for Abilene that she just passed by on the train and then Manifest became a solid, true place.

Sophie: It is with her. True places are [pause] always with you. Even if you move to another place, that place comes with you and when you go back it isn't the same because you know another place now, too.

Paige, from Lakeside, recognizes that physical places can be represented on maps, but the individual meaning that is ascribed to place evades representation, as it is unique to each individual. How and why a place is meaningful is often difficult to articulate, or to locate on a grid with delineated borders or landmarks because it has meaning that is contextual. Echoing Macfarlane, Massey, and Ingold, Paige understands that places are not only physical spaces, but they are socially constructed; they have meaning or stories ascribed to them that are unique to an individual's experience of that space. Sophie's reflection that places aren't 'the same' when you leave and return chimes with Massey's (2005) comment that "you can't hold places still" (p. 125).

In a later conversation, also in Lakeside, Norah and Thea continued this discussion: Norah: Can a place be true? [pause] I think that it depends on how you are using the word place. Like if you are using it to describe place in the sense of 'the people make the place', I don't think that you can put it on a map. Because you can't 
describe the feelings, the sense of, like [pause] belonging, maybe. Or not belonging. Because belonging to place has a feeling but it's not easy to [pause] pinpoint exactly. You know, it shifts?

Thea: Yeah [pause] It is different for everybody. You couldn't just hand someone a map and say, this is what is true. Everybody knows different people [...] And knows the space differently. If I drew a map of this school it would be different from Norah's or Liam's. I would put what $I$ know, what I've [pause] felt there, or seen there. That can't be the same as where they've been or [...] what they've come to know.

My participants conceptualized place as a multifaceted social construction; a "meeting place" (Massey, 1994, p.154) or "meshwork" (Ingold, 2008, p. 3) rather than a permanent recording or set of coordinates. Norah's use of the word 'difficult' in relation to 'pinpoint' suggests that place is not a stable construct. For her, place is often a feeling that evades representation because it is changeable. Similarly, my participants suggest that discussing place is dependent on the definition employed, and on the experiences brought to the discussion. Places cannot have coherent identities because, as Thea notes, they each know place differently. Much like Ingold, Thea understands that each of them follows different paths or lines through the school, depending on 'what they've come to know'. Thea's use of the word felt suggests that, for her, maps are capable of recording subjective encounters with place. Macfarlane (2018) uses similar language, writing: "we would do well to recall these felt maps" (n.p).

Turning to a selection of my participants' maps now allows me to illustrate the ways in which three adolescents articulated their individual place-identities.

\section{Victoria}

\section{Mapping stories of place and identity}

Seventeen- year old Victoria lived with her parents and two older brothers in a block of attached housing in Kirkville. Victoria had never travelled beyond Toronto, but she shared dreams of doing so. While she reflected on the role of community and family on her understanding of Toronto, she often reiterated the importance of having her own space. In her journal, Victoria mapped her bedroom. 


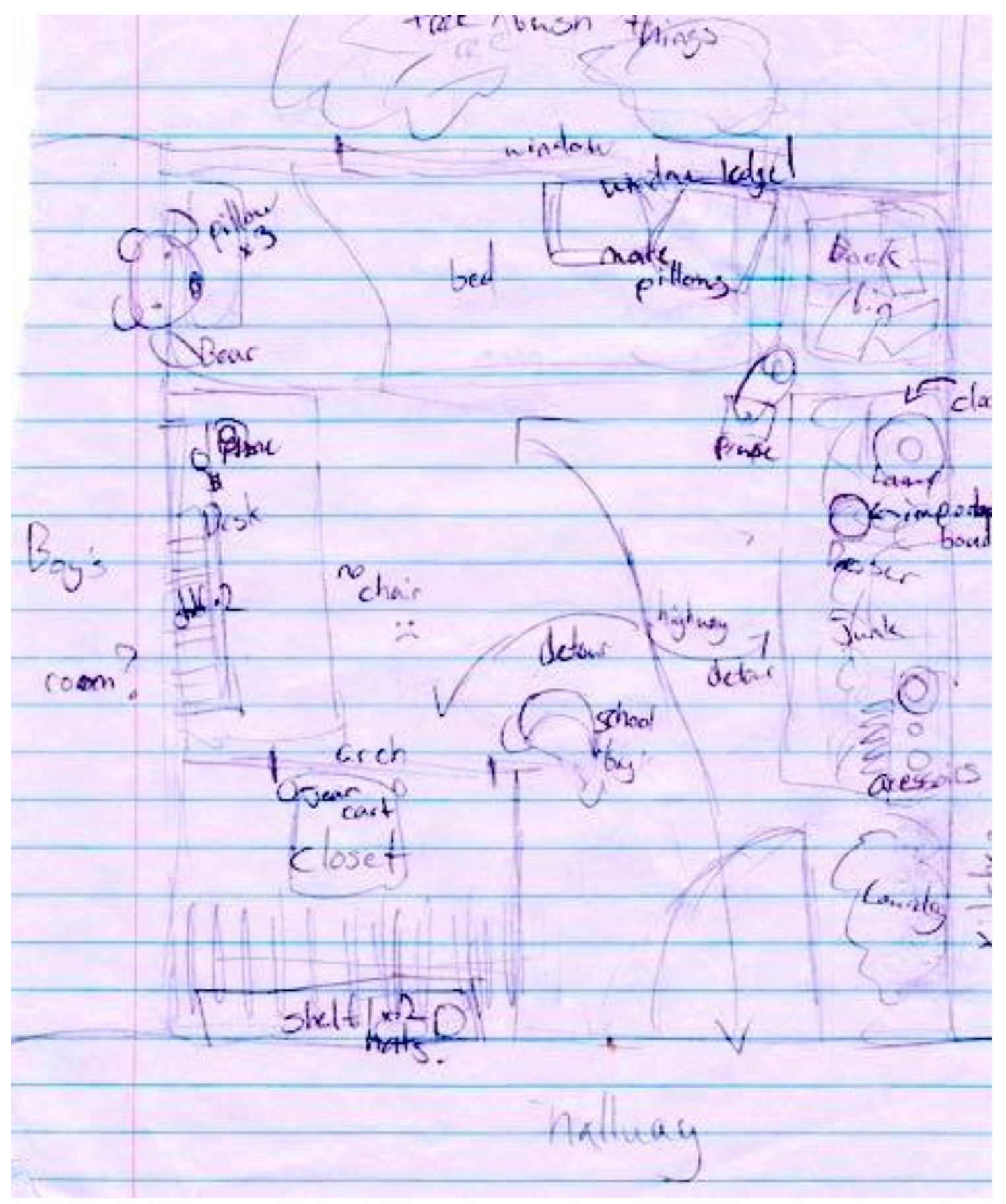

Figure 1. Victoria's map of her bedroom

During our interview, Victoria described her map to me:

Researcher: What did you decide to draw, then?

Victoria: I drew the one place where it is actually mine, and not my family's, and that would be my bedroom. It's the one place I [...] only I really know. The kitchen and that, well that is a shared space. But my bedroom is mine. [...] I've shown it from above [...] so you can see down, as if you were above. Looking down allows 
you to see the room from every perspective, from each of four directions. I've also included arrows and lines which are meant to show that you turn this way, that way [pause] and so you see this room how $I$ see this room.

Much like a grid map, Victoria's bird's eye sketch attends to specific physical details. The four walls of her bedroom are clearly marked, as are the windows, door, and hallway. Arrows indicate how to move through the space. Her repetition of 'seeing' and 'looking' suggests that, in creating her map, Victoria was focused on providing a visualization of this space, much like a cartographic map might do. Similarly, she references arrows, four directions, and perspectives, noting some degree of fixedness or stability. Victoria is clearly familiar with the conventions of road mapping. She understands that representing her bedroom as such will offer her viewer a particular perspective of this space, and a familiar method with which to navigate it.

And yet her map is intercepted with stories. While her bedroom had borders surrounding it, characteristic of cartographic maps (Ingold, 2016), the lines that Victoria has included in her sketch map are drawn along rather than across the surface-signifying habitation. Ingold (2016) writes, "when drawing a sketch map for a friend, I take my line for a walk [...] I weave a narrative thread that wanders from topic to topic, just as in my walk I wandered from place to place" (p.90). The idea of wandering chimes with Victoria's description, in that her narrative in relation to her map tells a particular story of this space that jumps from one thing to the next, as an insider might see this space. While she has included arrows, they do not move linearly across the page; she labels 'detours' that can be taken.

On the page, Victoria's bedroom is in the spotlight, with the other features of the house (kitchen, other bedrooms) given little attention. In our conversation, she repeats that her bedroom is 'hers'. In contrast, on the left side of her sketch, she has written 'boy's room?,' which vaguely indicates that her brother's room is adjacent to her own. The placement of the question mark suggests that, while she has a clear spatial awareness of her bedroom, she is disconnected elsewhere within the house. The level of detail provided about her own space contrasts with the question mark. Similarly, trees and 'things' are outside of her bedroom window. 'Things' suggests that what is beyond the room is not as important as what is inside, where objects are labelled and named with precision. The details that Victoria includes, through her careful, creative use of labelling, indicates that this space reflects her personal identity. Rather than "aspiring solely to the neutral organization of data" (Macfarlane, 2007, p. 143), Victoria's map visually tells a story of who she is in this place. The subjectivity of the map is created through her use of style-through her focus on certain aspects of the space, and its absences. The lack of objectivity in its style indicates that Victoria is aware that her map represents her personalized encounter with this place.

Victoria's understanding that place is not static but rather a 'bundle' of lines or trajectories also came across during our discussion groups in response to the research texts: Victoria: Blink and Caution takes place in Toronto [...] and it talks about subway stops and stores and streets that $d o$ exist-- like Yonge and Bloor, like Kipling and the 401. The geography of the book is accurately represented [...] you could take the streets and follow them, if you did not know [...] which street leads where. A guidebook of sorts [pause] because you could not know the city and use it to get around. But the book does not remind me of the place [pause] where I live. Of what 
I see on my streets [...]. Blink does not see what I see. He sees things differently, depending on where he is going or doing. Even though we both name it Toronto. While Blink, the narrator, provided an accurate road map of Toronto's city streets (insofar as you 'could follow them' in real life) his fictional representation of Toronto does not match Victoria's visceral experience of the city. "We both name it Toronto," she explains. In other words, even though the place is the same, by name, it is very much a different encounter. Here, again, Ingold's map distinction is useful: as it exists on the page, the cartographic map of Toronto provided by Blink is only able to take us so far. Ingold would refer to Blink's description as a route rather than a path. In meandering through Toronto's streetscape, Victoria has "la[id] a trail on the ground in the form of footprints, paths and tracks" (Ingold, 2016, p. 82). Victoria's understanding of Toronto does not tell the same story as Blink's; her phrase 'what I see on the streets' reiterates her acknowledgement of this. Children's geographers Tracy Skelton and Katherine Gough (2013) explain that "young people are not only in the city, but they are of the city; their lives are shaped by urban dynamics and they themselves are significant actors in, and creators of, the city" ( $p$. 457). Victoria's reference to 'my streets' (much like the map of 'her bedroom') illustrates that she is a 'significant actor' in place. She has a degree of ownership over her meaningful places, and she understands place as a dynamic reflection of identity rather than a fixed set of coordinates or set of plotted landmarks.

Calla

When I met seventeen-year old Calla from Kirkville, she had always lived in the same house with her family. While attending to the social elements of place, Calla's reflections continually provided me with a strong visualization of her physical surroundings:

Calla: My house is this house that is sort of in a somewhat suburban area, it is in front of a park [...] I have a front garden and a back garden, and they are very big for an average house [...] the front garden is lined with a picket fence, and on both sides of the sidewalk in front of the house there is plants growing. We have hydrangeas and roses, vegetables grow in summer - rows of beans and radishes [...] they go right up against the sidewalk. I am responsible for the garden, the watering and weeding. And my house is pretty big, it's not a mansion or anything $[\ldots]$ it has a basement, small attic, very small; [...] Um, the living room is where I spend most of my time sketching comics [...] and in the dining room there is a computer, um, that my family shares.

Much like Victoria, Calla introduces herself initially through the aesthetics of a grid-map. Descriptors such as 'very big,' 'small,' 'in front of,' 'lined,' and 'both sides' help us to visualize this space as if we were passersby. 'Right up against,' 'lined' and 'in front of' seemingly add borders and lines across space, both characteristic of cartographic maps (Ingold, 2016). However, Calla's "spoken cartography" (Macfarlane, 2007, p. 141) includes clear remnants of experiences and relationships, particularly through her use of pronouns. This is '[her] house'. The attic is where her family ('we') stores stuff, while 'I' is employed in reference to the living room and the gardens. We learn that it is her responsibility to weed and water the gardens; that she draws comics in the living room; that the family computer is shared. 
Calla's attention to detail, specifically in relation to the garden, suggests that this is a salient feature of this place. Beyond providing a list, she carefully describes the park, the front and back gardens, and the names of the plants and vegetables that grow up against the sidewalks. Calla explains both gardens as 'very big for an average house' — in other words, her house is 'average', but her garden is not, conveying how she values this particular feature of her home. Calla later tells me that she is named after her mother's favourite lily. The social features of this space inform how the physical is enacted. For example, the act of gardening is a family event for Calla. Telling me that she was named after her mother's favourite flower eludes to a connection between the garden and the relationship she has with her mother. Being 'responsible' for the garden suggests that the physical space is governed by a set of rules or familial or social practices. In doing so, her map tells a story of her relations and the importance of her family to her everyday life (cf. Cuervo \& Wyn, 2017). Calla's narrative maps the lines along or the paths (Ingold, 2016) she takes through this place in a way that transcends a strictly grid-like representation.

Calla also reflected on her connection with a town in the United Kingdom where her father was born, and where her paternal grandparents still lived. In her journal Calla sketched this place, represented in comic-style which she described during our interview:

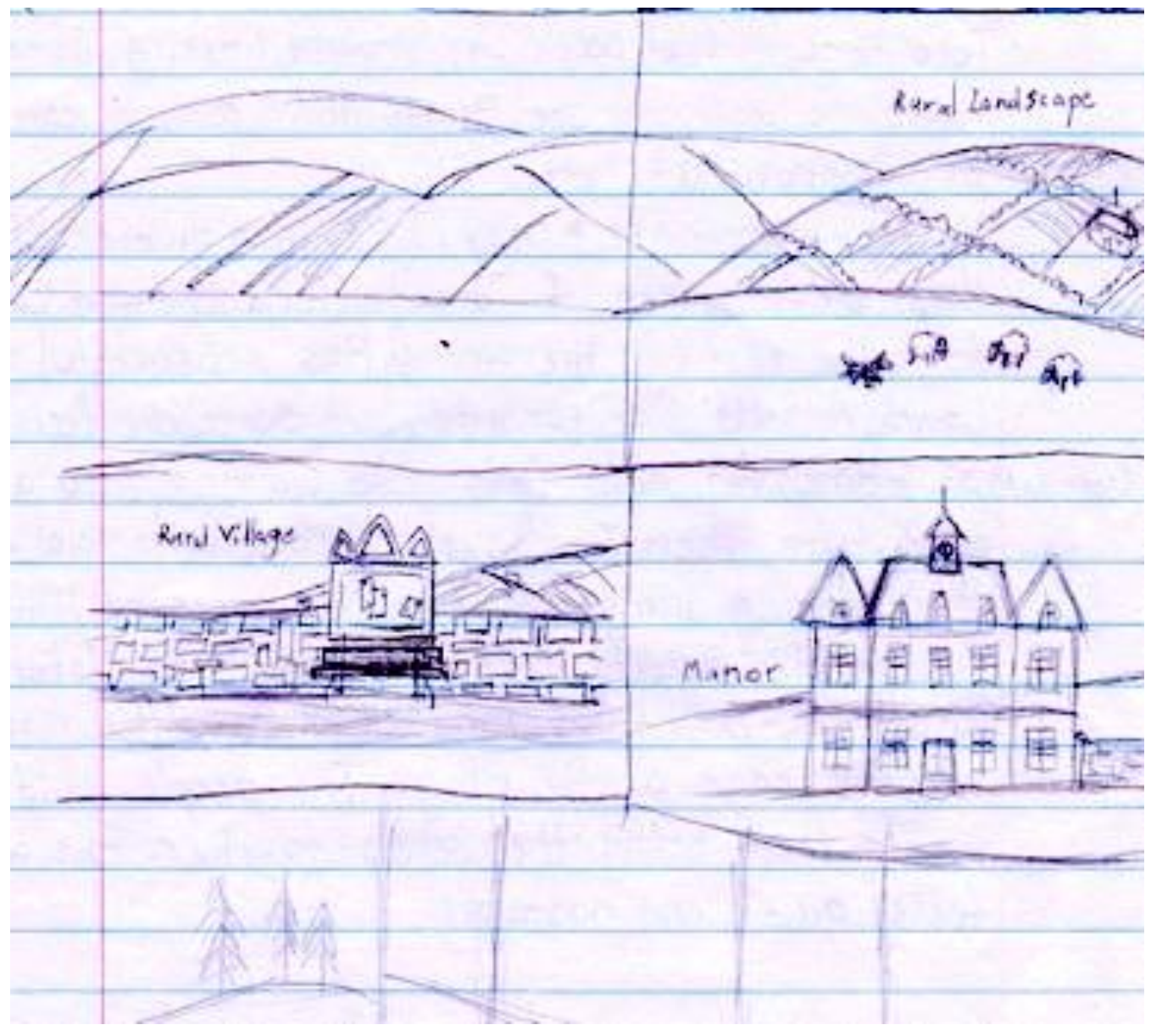

Figure 2. Irina's map of Dorset, England 
Calla: I really like the sort of patchwork [...]. You can look in the far distance and there is these farms, and fields, and they seem to go on forever [...] and they are sort of split by these little hedges [...]. Sometimes you see sheep with a sheep dog [...] and a man walking beside them. This is my grandmother's manor [...]. In this rural village you can see the landscape in the distance, but um, there is a stone wall [...]. The bricks are really big, there sorta squashed together, and they're uneven [...]. It is hard to tell, but I tried to draw a bench with a notice board on the top of it. I've seen a lot of those [...] little notices about get-togethers.

Researcher: So what does England mean for you, then?

Calla: Um, it means the ideal environment that I'd like to be in.

Researcher: Ideal, because it's small?

Calla: Small, yes, and close to nature.

As with the description of her home in Toronto, and much like Victoria's map, Calla's use of scale illustrates how the physical landscape is prominent in her identification with this place: the hills are large, taking up two squares of her sketch. In the bottom frame, the front steps of the manor are in the spotlight. If Calla meant for there to be a narrative thread woven through her comic, then placing the hills in the top frames would require the reader to begin their reading with the landscape, rearticulating its importance. In the middle squares, her grandmother's manor and the stone wall and notice board are given equal presence on the page. These middle frames are from an eye-level gaze, but the hills are still visibly prominent in the background. Calla's perspective shares how she has experienced this landscape: she always described the hills as being in the distance, but never any closer. Her repetitive labelling of this place as rural enunciates how she envisages this space. 'Rural' evokes idyllic, and it opposes the term suburban, employed to describe her house's location. While her focus is on the physical landscape, the social aspects of this place (the manor, the man walking, and the notice board) are integral to this place's story. For Calla, "the landscape was experienced as being part of the person and the person as part of the landscape" (Rönnlund, 2020, p. 129).

\section{Irina}

Seventeen-year old Irina from Kirkville lived with her parents in an apartment block close to the school. Having moved from Russia at age ten, Irina's place reflections often shifted between Toronto and Moscow. Irina's journal included a "cartographic narrative" (Travlou et al., 2008, p. 311) in which she reflected on spending time with her grandfather in Russia:

I remember lying down on the slope of the branches, the forest's pine smell would fill my nose as I lay on, and balanced on the not so wide birch tree. My grandfather was coming eventually [...] - I was patient. I could lie and watch the clouds for hours, breathing in the fresh air. Occasionally imitating bird calls at the pair of feathered friends above my head. My grandpa would eventually come to the berth of the forest. While we would walk the forest, we would discuss the forest, as quietly as possible. Sure, there weren't any bears, as far as we knew, but there were deer, lynx and wolves. I liked thinking of them walking below me as I sat up in the tree. Our time was mostly spent gathering mushrooms or just relaxing in the hum of the forest. Before I [pause] I never thought were my place was, I've moved 
enough to dissociate from such folly — but if anything — being in the heart of a forest [...] I always felt relaxed, at home.

Returning to Ingold's (2016) distinction between transport and wayfinding is helpful here. Wayfinders are "continually responsive to his perceptual monitoring of the environment [...] he watches, listens and feels as he goes, his entire being alert" (p. 80), while transported travellers are "rather moved from place to place." (p. 81). From the vantage point of a tree, wayfarer Irina reflects on what she sees below, above, and around her. She does not just describe her surroundings, but she interacts with them: Irina is connected to, and thus not separate from, the natural world and her grandfather.

Perhaps more than any other example thus far, Irina's story-map "provoke[s] a view from an unaccustomed angle" (Massey, 2005, p. 109). Macfarlane (2018) reminds us that grid maps have "eliminated our sense of the worth of map-as-story: of cartography that is self-made, felt, sensuous" (n.p). While Irina's description could evoke any forest, her careful braiding of language with memory maps this place in a way that a visual representation (or cartographic map) would have erased. Instead, her encounter with this place is "unmappable - too big, sprawling and changeable to be captured entire on paper or campus" (Macfarlane, 2018, n.p). Indeed, Irina's description prohibits us from finding this place on a road map, and even if we could it would not look the same. She has recalled an aesthetic and embodied encounter that holds no sense of permanence.

As a sharp point of contrast, in her place-journal, Irina sketched a map of her bedroom in Kirkville.

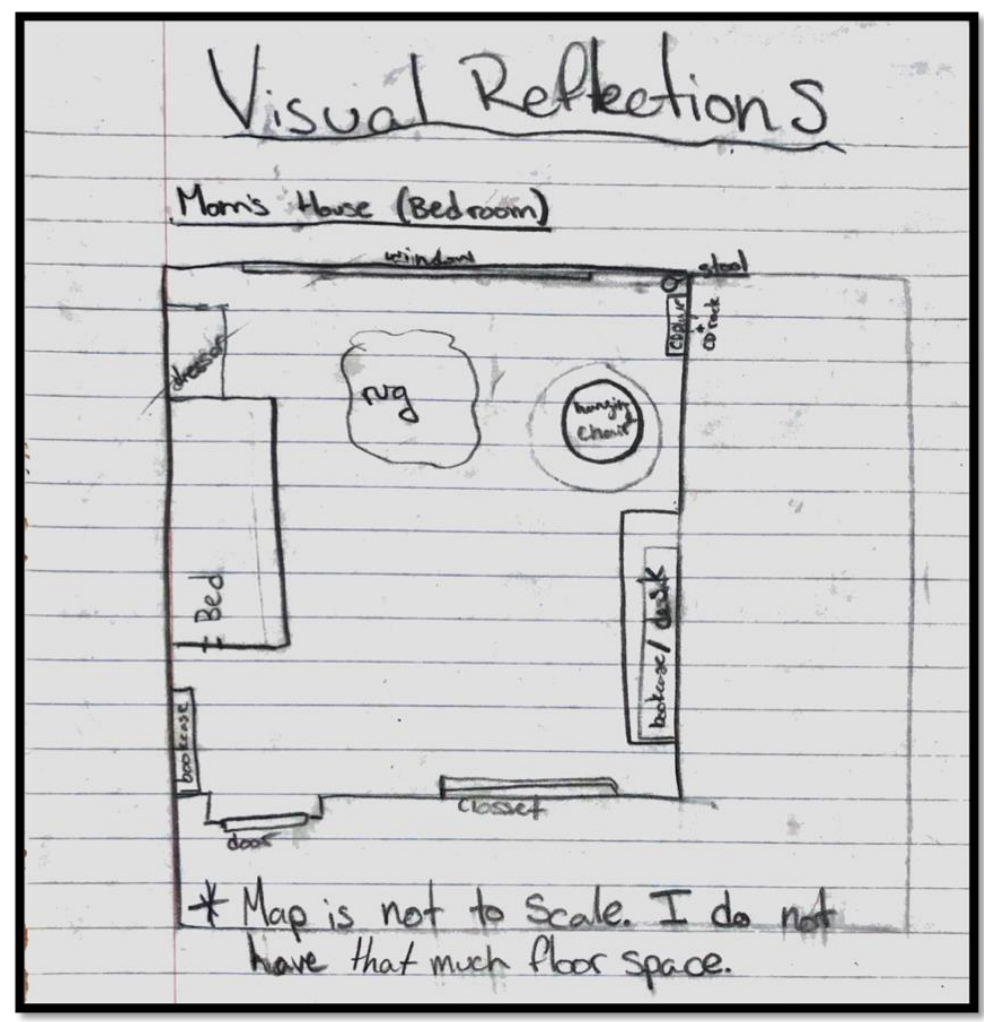

Figure 3. Irina's map of her bedroom 
While her narrative provided us with an intimate story-mapping of her time in the forest, her bedroom is given far less attention. Much like Victoria's map, the basic, grid-like features of the room are clearly delineated: her bedroom has four walls, a window, a door, and standard furniture. Irina's map, unlike her felt, cartographic narrative, provides a representation of space that is "independent of being" (Macfarlane, 2007, p. 142). There are no piles of clothing, arrows to indicate movement, or any evidence of it being lived in. Her disclaimer at the bottom is ultimately where this map's story is told: 'I do not have that much floor space'. Irina resents her lack of personal space within her house-- like Victoria, she desires a 'room of her own'.

\section{Conclusion}

Theoretically, through this paper I have sought to make connections between interdisciplinary conceptualizations of place and mapping, drawing on the work of Massey, Ingold, and Macfarlane. It is my hope that highlighting the connections between their work enriches our understanding of the dynamic intersections between place, identity, and mapping. For example, their focus on the influence of stories encouraged me to consider how my participants' place-encounters are not fixed but are shaped by their multiple journeys along paths and through places rather than simply across them. I was prompted to follow the paths represented in their maps, and to consider these paths as representations of their place-identities as becoming rather than being. I was encouraged to think about place as a 'bundle' - or a coming together of lines and trajectories. While these underlying theories and concepts guided my analysis, my participants' reflections clarified that this is how they think about place, too-- without my direct prompting. They do not envision place as a container, or a location that we simply move across. They understood that places 'move on' and that mapping place is a subjective, aesthetic encounter rather than a permanent recording of spatial data. My participants shared that a range of diverse places have informed their identities. Not only did my participants map physical places, but their representations told stories of how these places have been (and continue to be) shaped by their childhoods, families, peers, communities, and imagined futures. Subjectivity and lived experiences were imbued into their maps through a focus on style or ownership: how they chose to represent place spoke volumes about their imagined relations with these locations. My focus on the lives of adolescents living in rural and urban settings turns the spotlight on the experiences and perspectives of an often-underrepresented group of individuals.

Methodologically, this paper makes the case for employing story-mapping in our work with young people. The process of mapping became a kind of literacy that provided these youth the agency to rewrite and represent their multiple place-relationships. The flexibility offered by mapping meant that my participants could respond to their encounters in a way that felt most suitable to their place-experiences. Calla, for example, shared with me that she is a comic-strip artist, and her map was represented in comic-style. Victoria similarly chose to map her bedroom, which she highly values as a place of her own. Irina's narrative of being in the Russian forest with her grandfather was far more complex and insightful than the visual map she provided of her bedroom. Her narrative revealed salient details about her adolescent identity, particularly how she engages with the natural world, and the importance of family. If I had solely asked Irina to provide a visual sketch-map, most of these details would have been omitted. Their visual and narrative maps, in addition 
to our conversations about their maps during our interviews, provided me with an understanding of how these young people imagined and negotiated their spatial identities. The process of mapping asked my participants to engage critically and creatively.

While the flexibility of mapping as a method with young people was an asset, in that it left the decision-making with the participant, the interviews were vital to my analysis. Inevitably, the maps, when viewed on their own, left me with questions and areas for further exploration. I also argue that the participants, when asked to reflect on their maps, provided more detail, therein prompting them to think more critically and carefully about their responses. While I only shared two brief snippets of data from the discussion groups, I found that the conversational nature of the interviews and discussion groups created a safe space for the participants to put their conceptualizations of place into action. Massey (2005) writes that narrative is "about interaction and the process of the constitution of identities" (p. 71, emphasis in original). Words like 'think,' 'maybe,' and the questions posed between participants ('you know?) illustrate how we were working together to shape understandings of place. They drew on personal experiences but also used the text and each other's encounters as a springboard for thinking through these complex issues.

In the context of our increasingly fluid, unstable, and mobile lives, I argue that young people build meaning through their connections with people and places over time. Place is not just a static point on a map, but, for these young people, also a site of stories, experiences, feelings, and memories that connect to-- and indeed help establish - their identities and make sense of their life trajectories. My work moves us away from thinking about place $o r$ identity as fixed or static and argues for a framework of mapping adolescent identity that privileges the dynamism, perception, and subjectivity of our encounters. Drawing on my participants' varied responses, I have illustrated the ways in which mapping provides young people with the agency to articulate, represent, and re-story their identities. In focusing on the affordances of place, through mapping, I have reminded us of the tremendous potential for place to incite identity-work in the critical literacy classroom.

\section{References}

Cahill, C. (2000). Street literacy: Urban teenagers' strategies for negotiating their neighbourhood. Journal of Youth Studies, 3(3), 251-277.

Catling, S. (1988). Maps and mapping. In D. Mills (ed.), Geographical work in primary and middle schools. Geographical Association.

Cuervo, H., \& Wyn, J. (2017). A longitudinal analysis of belonging: Temporal, performative and relational practices by young people in rural Australia. Young, 25(3), 1-16.

Charlton, C., Wyse, D., Cliff Hodges, G., Nikolajeva, M., Pointon, P., \& Taylor, L. (2011). Place-related identities through texts: From interdisciplinary theory to research agenda. British Journal of Educational Studies, 59(1), 63-74.

Charlton, E., Cliff Hodges, G., Pointon, P., Nikolajeva, M., Spring, E., Taylor, L., Wyse, D. (2014). My place: Exploring children's place-related identities through reading and writing. Education 3-13: International Journal of Primary, Elementary and Early Years Education, 42(2), 154-170.

Cliff Hodges, G. (2010). Rivers of reading: Using critical incident collages to learn about adolescent readers and their readership. English in Education, 44(3), 181-200. 
Cliff Hodges, G. (2016). Researching and teaching reading: Developing pedagogy through critical enquiry. Routledge.

Comber, B. (2016). Literacy, place, and pedagogies of possibility. Routledge.

Comber, B. (2013). Schools as meeting places: Critical and inclusive literacies in changing local environments. Language Arts, 90(5), 361-371.

Compton-Lilly, C., Papoi, K., Venegas, P., Hamman, L., \& Schwabenbauer, B. (2017). Intersectional identity negotiation: The case of young immigrant children. Journal of Literacy Research, 49(1), 115-150.

Farrugia, D. (2014). Towards a spatialised youth sociology: The rural and the urban in times of change. Journal of Youth Studies, 17(3), 293-307.

Farrugia, D., \& Wood, B. E. (2017). Youth and spatiality: Towards interdisciplinarity in youth studies. Young, 25(3), 209-218.

Gieseking, J. J. (2013). Where we go from here: The mental sketch mapping method and its analytic components. Qualitative Inquiry, 19(9), 712-724.

Haukanes, H. (2013). Belonging, mobility and the future: Representations of space in the life narratives of young rural Czechs. Young, 21(2), 193-210.

Holloway, S. L., \& Valentine, G. (2000a). Children's geographies: Playing, living, learning. Routledge.

Holloway, S.L., \& Valentine, G. (2000b). Spatiality and the new social studies of childhood. Sociology, 34(4), 763-783.

Ingold, T. (2008). Bindings against boundaries: Entanglements of life in an open world. Environment and planning A: Economy and Space, 40(8), 1796-1810.

Ingold, T. (2015) The life of lines. Routledge.

Ingold, T. (2016). Lines: A brief history. Routledge.

Kitchin, R. (1994). Cognitive maps: What are they and why study them? Journal of Environmental Psychology,14(1), 1-19.

Kitchin, R., \& Dodge, M. (2007). Rethinking maps. Progress in human geography, 31(3), 331-344.

Leander, K., \& Sheehy, M. (Eds.). (2004). Spatializing literacy research and practice. Peter Lang.

Lynch, K. (1960). The image of the city. MIT Press

Macfarlane, R. (2007). The wild places. Granta Books.

Macfarlane, R. (September 22, 2018). Wizards, Moomins and pirates: The magic and mystery of literary maps. The Guardian.

https://www.theguardian.com/books/2018/sep/22/wizards-moomins-and-gold-themagic-and-mysteries-of-maps

Mackey, M. (2003). Researching new forms of literacy. Reading Research Quarterly, 38(3), 403-406.

Mackey, M. (2016). One child reading: my autobibliography. University of Alberta Press.

Massey, D. (1991). The political place of locality studies. Environment and Planning A, 23(2), 267-281.

Massey, D. (1994). A global sense of place. Marxism Today, 35(6), 24-29.

Massey, D. (2005). For space. SAGE.

Massey, D. (2013, February 1). Doreen Massey On Space. Social Science Bites Podcast. https://www.socialsciencespace.com/2013/02/podcastdoreen-massey-on-space/ 
Mills, K.A., \& Comber, B. (2013). Space, place and power: The spatial turn in literacy research. In K. Hall, T. Cremin, B. Comber, \& L. C. Moll (Eds.), International handbook of research in children's literacy, learning and culture (pp. 412-423). John Wiley \& Sons.

Moje, E. B. (2004). Powerful spaces: Tracing out-of-school literacy spaces of Latino/a youth. In K. M. Leander \& M. Sheehy (Eds.), Spatializing literacy research and practice (pp.15-38). Peter Lang.

Moje, E.B. (2000). "To be part of the story": The literacy practices of gangsta adolescents. Teachers College Record, 102(3), 651-690.

Monk, J. (2019). Mapping the soft city: Using cognitive mapping to respond to Londonbased literature and explore the construction of teenage place-related identity. Children's Geographies, 17(2), 162-176.

Pennycook, A. (2010). Language as a local practice. Routledge.

Powell, K. (2010). Making sense of place: Mapping as a multisensory research method. Qualitative Inquiry, 16(7), 539-555.

Rönnlund, M. (2020). 'I Love this Place, but I Won't Stay': Identification with place and imagined spatial futures among youth living in rural areas in Sweden. Young, 28(2), 123-137.

Sheehy, M. (2009). Place stories: Time, space and literacy in two classrooms. Hampton Press.

Sheehy, M. (2013). What does human geography have to do with classrooms? In K. Hall, T. Cremin, B. Comber, \& L. C. Moll (Eds.), International handbook of research on children's literacy learning and culture. John Wiley \& Sons.

Skelton, T., \& Valentine, G. (1998). (Eds.). Cool places: Geographies of youth cultures. Routledge.

Skelton, T., \& Gough, K. V. (2013). Introduction: Young people's im/mobile urban geographies. Urban Studies, 50(3), 455-466.

Spring, E. (2015). Where are you from?: Locating the young adult self within and beyond the text. Journal of Children's Geographies, 14(3), 356-371.

Spring, E. (2016). The experiences of two migrant readers: Freedom, restriction, and the navigation of adolescent space. Jeunesse: Young People, Texts, Cultures, 8(1), 227-247.

Spring, E. (2017). Empirical approaches to place and the construction of adolescent identities. In C. Beauvais \& M. Nikolajeva (Eds.), The Edinburgh Companion to Children's Literature (pp.112-134). Edinburgh University Press.

Spring, E. (2018). "Without Manifest, none of the book would have happened": Place, identity, and the positioning of Canadian adolescent readers as literary critics. Children's Literature in Education: an International Quarterly, 49(2), 101-118.

Street, B. (2017). Multiliteracies reconsidered: A "pedagogy of multiliteracies" in the context of inquiry-based approaches. In R. Zaidi \& J. Rowsell (Eds.), Literacy lives in transcultural times. Routledge.

Travlou, P., Eubanks Owens, P., \& Ward Thompson, C., \& Maxwell, L. (2008). Place mapping with teenagers: Locating their territories and documenting their experience of the public realm. Children's Geographies, 6(2), 309-326.

Vanderpool, C. (2010). Moon over manifest. Random House.

Wynne-Jones, T. (2011). Blink and caution. Candlewick Press. 


\section{Author Biography}

Dr. Erin Spring is an Assistant Professor in the Werklund School of Education at the University of Calgary where she teaches and researches in the areas of young people's texts and cultures. Her research projects are united thematically by a shared investment in stories and storytelling as a way of articulating adolescent identity development, with a particular focus on the influence of place. She is on the executive committee of the Association for Research in the Cultures of Young People. 